\title{
REGENT ADVANCES IN THERAPEUTIC (INDUCED) MALARIA
}

BY

G. DE M. RUDOLF, Bristol

As experience has accumulated with the extended use of malaria for therapeutic purposes new and interesting observations have been made. Some of these are of value to the malariologist, some to the neurologist, some to the psychiatrist. This article is an attempt at a summary of the more important observations that have been made within recent years. Up to the year 1926, the position of therapeutic malaria was summarized in an earlier work, so that only new facts that have been brought to light since that date will be recorded. Confirmatory evidence will not be described.

\section{INDICATIONS}

Dementia paralytica, or general paralysis, remains, as in earlier years, the most important disease suitable for treatment with malaria.

During the period under review many statistics have been published of the results obtained with malaria treatment alone; some of these are shown in Table I.

TABLE I

Treatment with Malaria Alone

\begin{tabular}{|c|c|c|c|c|c|c|c|}
\hline \multicolumn{2}{|c|}{ Author } & $\begin{array}{l}\text { Number } \\
\text { treated }\end{array}$ & Discharged & Improved & Unimproved & Dead & $\begin{array}{l}\text { Period of } \\
\text { observation }\end{array}$ \\
\hline \multicolumn{2}{|c|}{ Hinsie and Blalock } & 197 & $\begin{array}{l}\text { Per cent. } \\
21\end{array}$ & $\begin{array}{c}\text { Per cent. } \\
-\end{array}$ & Per cent. & Per cent. & \multirow{5}{*}{$\begin{array}{c}4-7 \text { years } \\
2 \quad, \\
3 \quad, \\
4 \\
9 \text { months to } \\
7 \text { years }\end{array}$} \\
\hline Bahr & . & 100 & 25 & 12 & 40 & 23 & \\
\hline ," & . & 100 & 30 & 13 & 27 & 30 & \\
\hline ," & • & 100 & 29 & 12 & 20 & 39 & \\
\hline Nicol & & 176 & 31 & 17 & $24 \cdot 4$ & 27 & \\
\hline
\end{tabular}

Table II shows results obtained by the use of malaria and arsenic in various forms, including tryparsamide (Tennent). 
TABLE II

Combined Treatment with Malaria and Arsenic

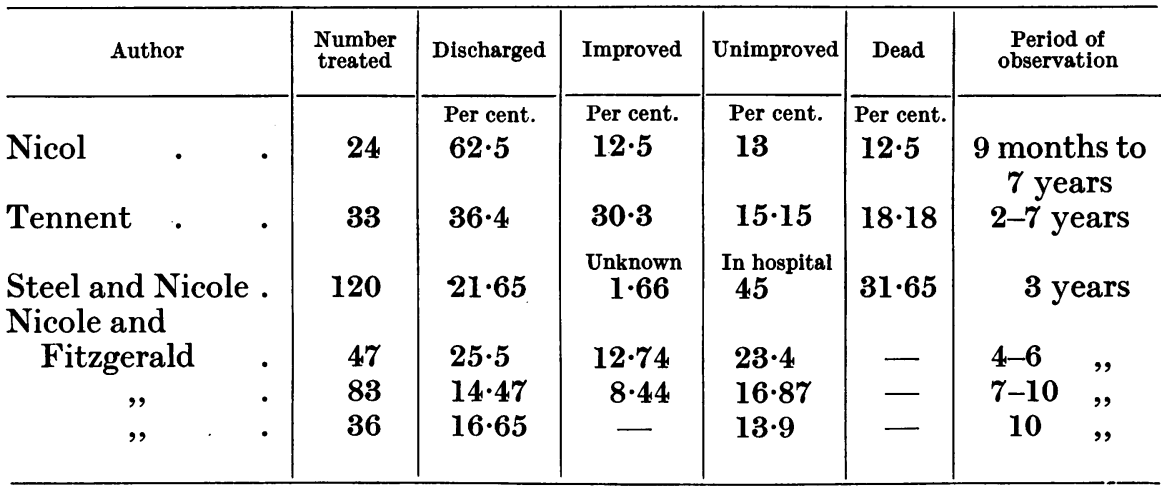

Table III records series of cases treated, some with malaria alone, others with arsenic in addition.

TABLE III

Treatment of Cases, Some with Malaria alone, Others with Malaria and Arsenic

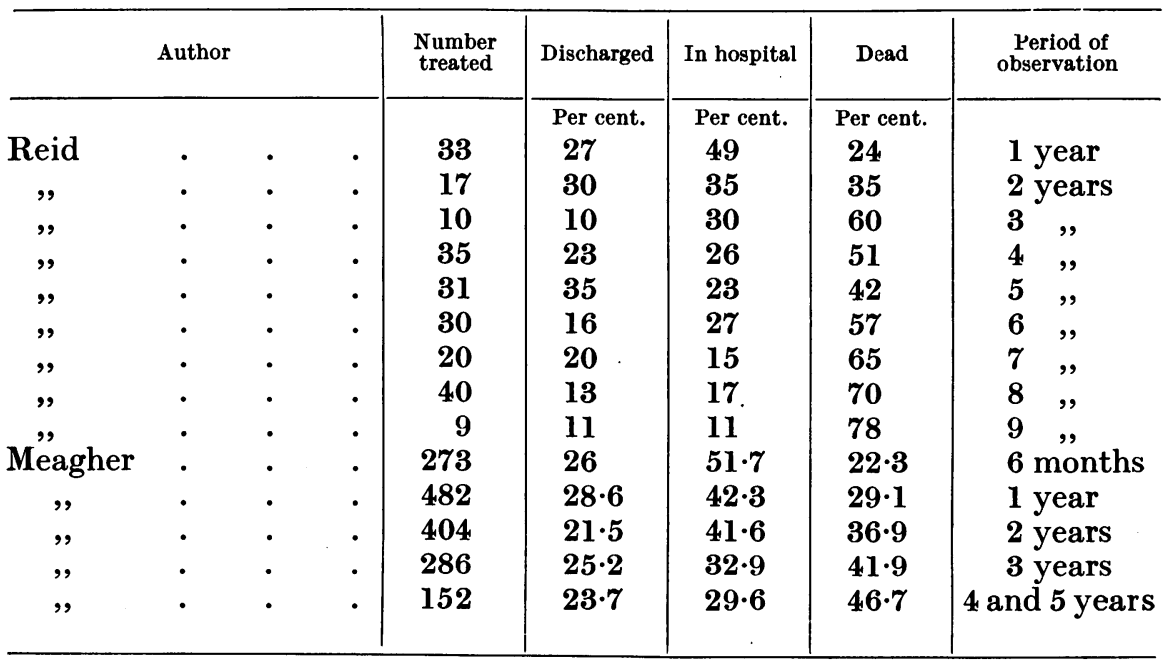

Bahr followed 100 patients year by year and found that up to four years after treatment there is little change in the numbers still discharged, i.e. these patients remained well. On the other hand, the numbers of the original 100 who were dead at the end of each year up to four years increased, the deaths being drawn from the group of unimproved cases (Table I). Table II confirms these results, as Nicole and his co-workers found that up to four to six years after treatment the percentage of discharges remained approximately constant. As with Bahr's cases, the cases remaining in 
hospital decreased. Table III shows results both in Reid's cases and in Meagher's collected series. After about six years after malarial therapy there is a marked fall in those still discharged, this being seen in both Nicole and Fitzgerald's series (Table II) and in that of Reid's (Table III). Concurrently, those still in hospital decrease greatly in numbers and according to Reid's results the deaths greatly increase.

The failure of so great a proportion, about 70-75 per cent. of paralytics, to undergo good remissions after treatment has led many writers to endeavour to determine the most favourable types of case for treatment.

Sex.-There is little or no difference between the benefits conferred by malarial therapy in the two sexes, although Hinsie and Blalock found that females lived longer than males.

Age.-The influence of age appears to be somewhat indefinite. Although Nicol in a series of 200 cases and Caldwell, who collected 579 cases treated in the London County Mental Hospitals, found that the age of the patient was not related to the treatment, Ferraro and Jong stated that the older the patient the less is the probability of improvement. The present writer found that from two to five years after treatment of 32 patients aged 21-40 years, 43.8 per cent. were discharged and $31 \cdot 2$ per cent. were dead ; of 36 aged from 41-50 years, $36 \cdot 1$ per cent. were discharged and $41 \cdot 6$ per cent. dead ; whilst of 20 cases aged 51-65, 20 per cent. were discharged and 75 per cent. were dead. Reid, in a study of 225 cases, reports that the average age of the patients at home was 41 years, whereas the average age of those still in hospital was 46 years and of those dead 45 years.

Primary Sore.-Caldwell found that the length of time from the appearance of the primary syphilitic sore to the malaria bears no relation to the results of the treatment. Dattner states that more favourable results are obtained in those whose syphilis has not been treated than in those to whom treatment has been given.

Duration of General Paralysis.-This bears a definite relation to the prognosis. Thus Marino found that his complete remissions occurred in patients in whom the duration of the general paralysis was from 14 days to two and a half years, whilst the incomplete remissions showed durations of from five months to three years. Caldwell reported that the discharged cases gave an average duration of 8.6 months (varying from 0.5 to 62 months), the improved of 12.7 months (from 1 to 108 months), the unimproved of 19 months (from 0.5 to 156 months) and those who died of $14 \cdot 7$ months (from 0.5 to 132 months). Reid found that the patients discharged showed an average duration of seven months, those still in hospital of 14 months and those dead of 12 months.

Table IV shows results obtained by two authors. The table shows that although the percentage of good improvements is less and the deaths are more amongst the cases with the longer history, remissions may occur with any duration of the disease, so that the treatment should be given to all 
cases, however great the duration of the disease before treatment is commenced.

TABLE IV

Duration of General Paralysis

\begin{tabular}{|c|c|c|c|c|c|c|c|}
\hline \multicolumn{3}{|c|}{ Author } & Duration & Number treated & Remissions & Discharged & Dead \\
\hline $\begin{array}{c}\text { Nicol } \\
\text {," } \\
, \\
\text {, } \\
\text { Rudolf } \\
\text {," } \\
\text { ", }\end{array}$ & $\begin{array}{l}\dot{.} \\
\dot{.} \\
\dot{.} \\
\dot{.} \\
\dot{.}\end{array}$ & $\begin{array}{l}\dot{.} \\
\dot{.} \\
\dot{.} \\
\dot{.} \\
\dot{.}\end{array}$ & $\begin{array}{c}\text { Months } \\
\text { up to } 6 \\
12 \\
18 \\
24 \\
36 \\
\text { over 36 } \\
\text { up to } 6 \\
7-18 \\
19-168\end{array}$ & $\begin{array}{r}83 \\
51 \\
18 \\
6 \\
10 \\
6 \\
25 \\
22 \\
18\end{array}$ & $\begin{array}{c}\text { Per cent. } \\
50 \cdot 6 \\
35 \cdot 3 \\
16 \cdot 65 \\
0 \\
20 \\
0 \\
- \\
- \\
-\end{array}$ & $\begin{array}{c}\text { Per cent. } \\
- \\
- \\
- \\
- \\
- \\
64 \\
40 \cdot 9 \\
11 \cdot 1\end{array}$ & $\begin{array}{c}\text { Per cent } \\
- \\
- \\
- \\
- \\
- \\
24 \\
40.9 \\
55.5\end{array}$ \\
\hline
\end{tabular}

Types of General Paralysis.-The majority of writers have found that the expansive type of general paralysis has a good prognosis. Thus although Ferraro and Jong state that but 29 per cent. of these cases remitted, Bunker and Kirby report 67 per cent., Flick 62.5 per cent., and Nicol $55 \cdot 25$ per cent. of 47 cases, McIntyre and McIntyre report 55 per cent. of 20 cases, Rudolf 44.7 per cent. and Caldwell 40.3 per cent. of 215 cases. Hinsie and Blalock also give this type as that with the best prognosis.

Manic types are stated to show the best results by Pilcz and by Bunker and Kirby ( 67 per cent. of cases). Nicol reports $47 \cdot 8$ per cent. of remissions in 23 of this type, Ferraro and Jong 41 per cent., Caldwell 38.4 per cent. in 55 cases. Hinsie and Blalock also found that a large number of cases of this type improve. Of the depressed cases, Ferraro and Jong report that 66 per cent. improve, Nicol 48.25 per cent. of 29 cases, Caldwell 15.7 per cent. of 106 cases. Of the cases of simple dementia, best results were obtained by Nicol, who discharged 25.35 per cent. of 75 cases, by Caldwell $15 \cdot 7$ per cent., by Bunker and Kirby 12 per cent., and by McIntyre and McIntyre also 12 per cent. (in 56 cases). Pilcz reports good results with this type. Of the stuporose and confused types, Caldwell reports 23.1 per cent. discharges amongst 45 cases and Rudolf $13 \cdot 6$ per cent. discharges amongst 22 cases. Pilcz and also Hinsie and Blalock obtained poor results.

The differences found by the various writers are, no doubt, due to some extent to the possibility of classifying the same case in more than one group.

Physical Condition.- Of 22 cases reported elsewhere as being in 'good" or ' fairly good' physical condition at commencement of treatment, 54.24 per cent. were discharged and 18.2 per cent. had died. Of 26 cases in moderate physical condition, $\mathbf{3 4 . 6}$ per cent. were discharged and the same proportion died, and of 39 cases in 'poor' or 'very poor' condition only 
23 per cent. were discharged and $\mathbf{7 6 . 9}$ per cent. had died from two to five years after treatment.

Wassermann Reaction.-The present writer found that of 63 cases who gave $a+40+$ or +40 (Mann and Partner technique) positive reaction in the cerebrospinal fluid, 41.3 per cent. were discharged. Of 14 who gave a $+20+$ or $a+20$ reaction, $28 \cdot 6$ per cent. were discharged, whereas of 10 giving a $+8+,+8$ or +4 reaction only 10 per cent. were discharged.

Condition after Discharge.--Investigations have been made with regard to the re-establishment of discharged cases. Meagher reports that of 404 cases discharged from mental hospitals, one-third were fully re-established, in one-third the disease was arrested, whilst in the remaining one-third the process was retarded only.

Caldwell found that of 101 patients from six months to five years after discharge, 73 per cent. were working. One.man was engaged on building and assembling engines for the Schneider Trophy competition, one was a solicitor's clerk, and one, who was on the staff of a newspaper, had been promoted since his discharge. The present writer reported the case of a patient who since discharge from Claybury Mental Hospital had been working as an accountant for two and a half years. Reid reports that amongst his patients treated from one to five years previously 16 per cent. were at work and 8 per cent. able to work ; of those treated from six to nine years previously 6 per cent. were at work and 5 per cent. able to work. One patient, since discharge, had been promoted to a position with 20 men under his orders. Another had worked as an engine-driver for three years.

Meagher found that many of the discharged patients were unduly irritable and readily provoked in an argument, others tired more easily than before their illness. Where married life had been resumed, many of the recovered patients became parents.

Tabes.-Costa, Moura and Pires found that optic atrophy was arrested by malaria in tabes. Incontinence was modified and vertigo passed off.

Cerebrospinal Syphilis.-Three years after treatment, 18 (69.2 per cent.) of 26 cases of cerebrospinal syphilis were improved and in good condition (Neustadter).

Schizophrenia.-Yakubovsky obtained remissions in 30 per cent. of cases. Although this author advises that only early cases be treated, one patient was able to leave the hospital with a history of schizophrenia of four and a half years. Nineteen cases were treated by Belleri. Favourable results were obtained in six (31.58 per cent.) of which five were hebephrenic and the sixth catatonic in nature.

No satisfactory results were obtained in 19 chronic cases treated by Wizel and Markuszewicz, but remissions persisting for several months were obtained in intermittent types. In four acute cases, successful results are reported.

Levi-Bianchini and Nardi treated 476 cases of non-syphilitic psychosis 
with malaria. Of schizophrenics 8 per cent. were cured and 16 per cent. improved.

Manic-depressive Psychosis.-Levi-Bianchini and Nardi obtained 23 per cent. of cures and 20 per cent. of improvements by means of malaria therapy.

In a group of acute and chronic post-infective, arteriosclerotic and endogenous psychoses about 10 per cent. good results were obtained.

Oligophrenia.-Malaria is of no value for this condition (Levi-Bianchini and Nardi).

Epilepsy.-Ramsay treated six cases of idiopathic epilepsy. In four cases, a temporary reduction of fits occurred, followed by an increase. One patient showed a permanent reduction of fits, and one a cessation, but death occurred one month after the malaria. Levi-Bianchini and Nardi state that malarial therapy is of no value in epilepsy.

\section{MENTAL GHANGES}

The hallucinations which may be associated or follow malarial therapy are apparently more common in men than in women. Kihn observed 28 cases of hallucinosis following the treatment, none of which were in women. Nicol observed the condition in only 2 per cent. of 200 females treated. The present writer had previously reported the condition in 22.5 per cent. of 40 male cases and Leroy and Médakovitch found the condition in 10 per cent. of cases. Masquin and Borel state that fluctuating hallucinations of all the senses are relatively frequent, auditory being more common than visual. The hallucinations may persist for a very short period only and special observation is required in order not to miss their fleeting presence.

Masquin and Borel state that hallucinations occurring during the febrile period tend to clear up, and Leroy and Médakovitch found that most of the hallucinated cases recovered. Kihn did not see a favourable outcome in any of his 28 cases and Wagner-Jauregg (cited by Meagher) considers the presence of hallucinations so unfavourable that the malaria should be terminated.

The paraphrenic states or the late psychoses occurring after treatment have been discussed by Masquin and Borel. These authors describe these conditions as confusional, hallucinatory, systematized, stuporose, with ideas of reference, manic-depressive, hypochondriacal, depressive and catatonic. With regard to schizoid reactions, four cases of hebephrenia and one of catatonia developed in Nicol's series of 200 females. A typical dementia præcox reaction was found by Ferraro and Jong in four cases out of 120 treated.

An improvement in power to form moral judgments was found by Weisfeld in 45 per cent. of 29 cases treated. In 56 per cent. improvement in attention developed and improvement in manual speed in 61 per cent. Tests were also used for memory, impressionability, the mental horizon and imaginative power, calculation, intellectual activity, intelligence and handwriting. In these tests 68-78 per cent. of the 29 patients improved after 
treatment. Claude and Masquin have produced a series of tests for estimating the degree of intellectual recuperation of general paralytics.

\section{PHYSICAL CHANGES}

Nicol records that of the discharged cases in his series of 200 treated cases, nearly all showed an increase in weight of from a few pounds to 1 stone. Those patients who developed partial remissions showed greater gains, of from 2 to 3 stone, whilst those remaining in hospital with marked mental reduction, increases of from 2 stone to 6 stone occurred. On the other hand, Cheney and Warner, in 33 patients, found that those who improved mentally showed an average gain of $4 \mathrm{lb}$., whereas those who gave no mental improvement gained about $\frac{1}{2} \mathrm{lb}$. each.

Reflexes do not show much improvement, and in unimproved cases are frequently worse, although coordination, ataxia, tremors and speech were all favourably influenced in the improved cases (Ferraro and Jong).

Reid, examining his treated patients, found that all patients remaining in hospital showed pupillary changes, 60 per cent. exhibiting unequal pupils with lack of contraction to light. Of the cases discharged to their homes, 87 per cent. showed pupillary changes. Approximately the same proportions of patients still in hospital and of those discharged to their homes showed slurring of speech, absent kneejerks and extensor plantar responses.

\section{PATHOLOgical Ghanges}

The changes in the cerebrospinal fluid accompanying malarial therapy have been divided into four periods by Käfer. The first period is during the malaria in which there is attenuation of the fluid pressure. The second period, named primary post-malarian period, extends up to one year from the termination of the fever and shows a reduction of the pleocytosis. This reduction is continued and extended in the third or secondary post-malarian period which lasts until the end of the second year. During the fourth, or later, period the reactions may become normal.'

According to Ferraro and Jong a close correlation between the serological and clinical improvements sets in within 35 months of treatment. Within two to three years after treatment these authors found that 86 per cent. of cases gave a negative Wassermann reaction in the blood and 68 per cent. a negative in the cerebrospinal fluid.

Of cases examined from 6 to 24 months after treatment with malaria only, two (18.2 per cent.) of 11 discharged cases gave negative reactions in the serum and the same number in the cerebrospinal fluid. Of 12 cases who improved, one (8.3 per cent.) gave a negative Wassermann reaction in the serum and two (16.6 per cent.) in the fluid. Of 40 unimproved cases seven (17.5 per cent.) gave a negative reaction in the blood and three (7.5 per cent.) in the fluid (Bahr and Bruetsch). Bunker found that in 47 cases examined at least two years after treatment, the Wassermann reaction in the cerebro- 
spinal fluid was negative in 21 per cent., improved in 38 per cent. and showed little or no change in $\mathbf{4 0}$ per cent. of cases. Caldwell reporting on cases from three to eight years after treatment found a higher percentage of improvements in the Wassermann reactions in the cerebrospinal fluid, but not in the serum, in those cases treated with malaria who showed the greater mental improvement. Of 44 cases showing a good or very good mental change, 11 (25 per cent.) gave a negative Wassermann reaction in the serum, and of 49 showing a moderate or poor mental result $13(26.5$ per cent.) gave a negative reaction. In the cerebrospinal fluid, of 34 cases in the first group, seven (20.6 per cent.) gave a negative reaction, and of 44 cases giving a moderate or poor mental result, only three $(6 \cdot 8$ per cent.) showed negative reactions after treatment.

In cases treated with malaria and arsenic, the same writer reports that in 22 patients showing good or very good mental changes, seven (31.8 per cent.) gave negative reactions in the serum and of 20 showing moderate or poor mental results, four (20 per cent.) showed negative reactions. Of 20 cases in the first group, five ( 25 per cent.) gave negative results in the cerebrospinal fluid, and of 18 cases in the second group, one (5.55 per cent.) gave such a reaction.

Tennent reported on cases examined over two years after treatment with tryparsamide and pyrexia (all treated with malaria, except two with relapsing fever). Of 27 cases, 10 (37 per cent.) gave a negative reaction in the serum, and eight (29.6 per cent.) in the cerebrospinal fluid.

A study of 350 cases year by year has been made by Nicole and Fitzgerald. These cases before treatment gave 99.2 per cent. positive reactions in the serum and 97.5 per cent. in the spinal fluid. Summarizing the results, of 227 cases up to three years after treatment 80.6 per cent. gave positive reactions in the serum, and $\mathbf{9 0 \cdot 2 6}$ per cent. in the fluid. From three to seven years after treatment the figures for 86 cases were $56 \cdot 65$ per cent. and $32 \cdot 8$ per cent. respectively. Finally, from seven to nine years after treatment the figures for 21 cases were $41 \cdot 5$ per cent. and $27 \cdot 85$ per cent.

Cell Counts.-As the years pass after treatment the percentage of cases showing reduced cell counts in the spinal fluid increases. In 350 cases reported by Nicole and Fitzgerald, 92 per cent. showed an increase of cells before treatment. Of 227 cases up to three years after treatment in 38.53 per cent. the increase persisted. Of 52 cases from three to five years after treatment 13.95 per cent. showed an increase, but in 55 cases from five to nine years after treatment only $\mathbf{7 \cdot 7 5}$ per cent. showed such increases.

Protein of Spinal Fluid and Serum.-Nicole and Fitzgerald also deal with globulin changes. In their series, 96 per cent. showed positive reactions before malaria. Of 279 cases up to five years after treatment $64 \cdot 15$ per cent. gave positive results ; of 34 cases from five to seven years after, 38.5 per cent.; and of 21 cases from seven to nine years, 9.55 per cent. gave positive reactions. Again, the progressive nature of the fluid changes is emphasized. 
Tennent gives the protein in mgm. per cent. before and after treatment .with tryparsamide and fever. In 25 cases in a series of 26, the protein was reduced in cases examined at least two years after treatment.

Immediately after malaria, the total serum protein shows no change, but the serum albumen falls. Ogden shows a fall of the average from 4.59 per cent. in 12 untreated cases to $4 \cdot 14$ per cent. in 12 treated cases with maxima and minima of 5.68 per cent. and 3.66 per cent. in the untreated paralytics and of 4.69 per cent. and 2.90 per cent. in the treated.

On the other hand, this worker found that the serum globulin average rose from $2 \cdot 38$ per cent. in the untreated cases to $2 \cdot 66$ per cent. in the treated, the maxima and minima being 3.25 per cent. and 1.75 per cent. in the untreated and 3.58 per cent. and 1.80 per cent. in the treated. The average percentage of globulin in the total serum protein was 33.4 in the untreated and 38.8 in the treated paralytics.

Bunker reports that immediately after malaria, the total protein in the spinal fluid averaged $156 \mathrm{mgm}$. per $100 \mathrm{c.cm}$. (16 cases), whereas before treatment the average was $192 \mathrm{mgm}$. One month after treatment, the figure was $124 \mathrm{mgm}$. (13 cases) and after three months it was $91 \mathrm{mgm}$. (10 cases). Two years after treatment 42 per cent. of 38 patients gave a reading of $50 \mathrm{mgm}$., 29 per cent. of from 50 to $75 \mathrm{mgm}$., and 21 per cent. a high average reading of $85 \mathrm{mgm}$.

Lange Reaction.-Before malaria, Nicole and Fitzgerald recorded that 92.9 per cent. of 350 cases showed a Lange reaction reaching up to 4 or 5 .

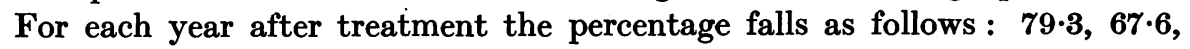
$50 \cdot 0,31 \cdot 2,30 \cdot 0,12 \cdot 5,0,0,0$.

In 25 cases treated by Tennent with tryparsamide and fever and examined at least two years after treatment, 11 (44 per cent.) showed negative Lange reactions, three (12 per cent.) reached up to 2 or 3 , and 11 (44 per cent.) reached 4 or 5 units.

Boltz Acetic-anhydride Tests.-In 176 fluids from untreated paralytics, Nicole and Fitzgerald found that $\mathbf{1 8 . 7 5}$ per cent. gave negative reactions. In 123 fluids examined within three years of the first course of malaria, 48.78 per cent. were negative and in $\mathbf{5 7}$ fluids tested over three years after malaria 89.12 per cent. gave negative results. The same authors report that shortly after malaria, the test may be positive although it has been negative before the treatment.

Flocculation Tests.-Nicole and Fitzgerald in their series of 350 cases found that there was no change in the percentage of positive results of flocculation tests in the serum even up to nine years after the initial malarial therapy. On the other hand, in the spinal fluid from seven to eight years after. malaria the percentage of positive results fell progressively from $\mathbf{9 7 . 5}$ per cent. to $52 \cdot 25$ per cent.

Permeability for Bromide.-Malamud and Wilson found that, in a series of 54 cases of untreated general paralysis, there was an increased permeability 
(index below 2.8). After cessation of malaria, there may be a further increase, followed by a fall in cases that subsequently show clinical improvement, the index rising to the normal of from $2 \cdot 8$ to $3 \cdot 2$. This fall does not occur in cases that show no clinical improvement. The authors found a relationship between the index and the quantity of iron in the cerebral vessels.

\section{HISTOPATHOLOGY}

Thorough investigations of the brains of cases dying during or after therapeutic malaria have been made by Geary and also by Wilson. During treatment, the lymphocytes are numerous in the meninges and the macrophages increase shortly after the termination of the fever. Infiltration of the vessels is very intense. Wilson found in 16 cases that within six weeks after treatment the changes are those of a severe diffuse general paralytic process. There is a strong glial proliferation with an increase of iron in the bloodvessel wall and the microglia. Numerous macrophages are present in the meninges.

From six weeks to two and a half years after treatment in 13 cases, a gradual improvement in the arrangement of the cortical layers and nerve cells was observed. Considerable reductions of infiltration, of glial proliferation, of iron in the vessels and of microglia occurred. During the latter part of the period, from one to two and a half years after treatment, secondary increases of macrophages in the meninges, of iron in the vessels and of microglia were found.

Six cases, dying from six months to two and a half years after treatment, showed scattered foci of intense inflammation with marked proliferation of the mesodermal tissue and with typical miliary gummata in one patient. In five of these cases spirochætes were found and no improvement appeared in the serological reactions.

Wilson defines three periods. The first is a period of exacerbation of all changes, commencing during treatment and persisting up to six weeks after treatment. The second is a period of restoration, which may continue for years ; whilst the third, occurring any time after six months, is the period of recrudescence, with a flare-up of the histological process. Of six cases which developed convulsive attacks after the malaria four showed well-marked changes of the paretic type, but in only one case were spirochætes found. Of a total of 29 cases in the periods of exacerbation and restoration, spirochætes were found only once.

Geary found that 10 cases out of 16 treated from three months to two and a half years previously showed definite improvement pathologically. Two cases treated 15 months previously showed no vascular lesions. Spirochætes were found in one case only, a congenital general paralytic, in place of the 60 per cent. of untreated cases in which these organisms are seen.

Kopeloff and Blackman found spirochætes, chiefly degenerate in type, in six out of 39 cases treated with malaria. These organisms were found in eight out of 10 untreated paralytics. 
Bruetsch points out that the histiocytes are very numerous in the perivascular spaces of the large vessels in the white matter, in the striatum and pons. The immediate response to the malaria is an activation of the reticuloendothelial apparatus, giving rise to the formation of macrophage tissue.

\section{MODE OF ACTION}

The most important contributions to this problem have been those of Eddison and of Power. Eddison finds that the leucopoietic functions are improved, the leucocyte reserve diminished and the leucocytes reduced in number in general paralysis. The reticuloendothelial system is flagging under the influence of chronic syphilis. Pyretotherapy stimulates this flagging system. Power believes that the reticuloendothelial system is stimulated, first, because malaria affects this system markedly; secondly, because there is a tendency to obesity after the treatment; and, thirdly, because there is an intimate relation between the system and the hæmatopoietic structures.

New formation of phagocytic tissue and stimulation of the endothelium, with reductions of the increased permeability of the brain capillaries, are thought by Bahr to be important contributing causes of the improvement.

The degree of pyrexia does not appear to be related to the clinical improvement, but Ferraro and Jong found a parallelism between the number of febrile paroxysms and the serological improvement.

Immunity.-Little new has been discovered with regard to immunity. James has shown that patients immune to one species of plasmodium are not immune to another. It was known earlier that patients immune to one strain of $P$. vivax are not necessarily immune to another strain of the same species. Ciuca found that of patients whose primary attack of malaria was terminated by quinine, 32 per cent. could be given a second course of malaria, but of those whose primary attacks had been allowed to run to spontaneous recovery, only 15 per cent. could be reinfected.

\section{TREATMENT}

Inoculation.-Cases should not be inoculated with blood from a patient suffering from splenic suppuration. Bahr and Bruetsch record such an inoculation with fatal results three and a half months later. The necropsy showed endocarditis of the mitral valve, a hæmorrhagic splenic infarct and minute embolic areas of softening in the left temporosphenoidal lobe. No doubt the presence of any suppurative process should negative the removal of blood for purposes of inoculation.

James has described further details relating to mosquito inoculation and has successfully used malignant tertian malaria. This worker found that the death-rate amongst the mosquitoes is high. Of 18,315 insects 
(A. maculipennis) used in 84 batches, only 5,862 lived sufficiently long to be available for infecting patients. The transmission of quartan malaria by mosquito is difficult, firstly, because there are but few patients who are infective to mosquitoes, and, secondly, because infected insects seldom infect people. James was unable to infect any persons with quartan fever from infected mosquitoes. Similar difficulties were met with regard to malignant tertian malaria. In 22 feeding experiments only one 'good infector' of mosquitoes was found.

The quality of the gametocytes is of more importance than their quantity. James now compares the infectivity of different cases on the basis of exflagellating male forms in the films made from moist chamber preparations of the patient's blood. With P. vivax, A. maculipennis is consistently negative when there is less than one exflagellating male to every 1,000 leucocytes in a film kept at $25^{\circ} \mathrm{C}$. for 15 minutes.

Reinoculation with malaria after failure to improve clinically does not, according to Nicol, appear to be very beneficial. Of 61 cases reinfected, very few improved physically and four were discharged, but all of the latter had commenced to improve before the second inoculation was performed. Reid found that of 32 patients reinoculated three were able to be discharged after the second course of malaria. Horn found that relapses of the syphilitic process occur only in patients with persistent abnormal cerebrospinal fluids. If the fluid is still positive a year after treatment, a second course of malaria should be given, which, Horn states, will often cause a rapid disappearance of the abnormal serological reactions.

Incubation Period.-A detailed study of the length of the incubation period has been made by James. He found that in mosquito-inoculated cases the mean duration in days of the period in primary attacks was $14 \cdot 102 \pm 0.077$ and in subsequent attacks $18 \cdot 12 \pm 0.55$. With blood inoculation the periods were $11 \cdot 205 \pm 0 \cdot 214$ and $18 \cdot 7 \pm 0 \cdot 455$. In 746 primary cases inoculated from mosquitoes the correlation-coefficient of the number of bites and the length of the period was $-\mathbf{0 \cdot 1 5 7} \pm \mathbf{0 . 0 2 5}$. When the bites were less than six in number, the incubation period was slightly longer than the average, and when more than six, there was a tendency for it to be shorter than the average. The period tended to be shorter from April to October and in excess of the average during the winter months. Latent infections have been reported by James and by Swellengrebel de Buch and Swellengrebel de Graaf. Periods of from 32 weeks three days to 45 weeks two days between mosquito-inoculation and the onset of malaria have been recorded by these observers. The number of bites varied from one to eight per patient.

Marino, inoculating subcutaneously with blood, obtained one incubation period of 43 days.

The length of the period between inoculation and the first typical malarial attack was found by Assendelft in $\mathbf{3 5 0}$ cases to vary with the number 
of P. vivax injected. When from 15,000 to $1,000,000$ were used, the period averaged 14.2 days; from one to 10 million, 12 days, and from 10 to 100 million, $10 \cdot 7$ days.

Temperature Chart.-The rise of temperature occurring as a reaction to the injection of the blood has been studied by Assendelft in 170 cases inoculated subcutaneously with $\mathbf{P}$. vivax. In eight cases a rise of temperature occurred upon the day of injection, in 29 upon the following day, in 27 cases on the second day, and in eight cases upon the third day after the inoculation. In 13 cases this pyrexia rose to over $39^{\circ} \mathrm{C}$. $\left(102 \cdot 2^{\circ} \mathrm{F}\right.$.). The pyrexia was apparently related to the number of parasites injected, as no case of injection fever occurred when less than one million parasites were used, but 40 per cent. of cases showed the fever when from one to 10 million were injected, and nearly 80 per cent. when more than 10 million were utilized. When the incubation period was under 11 days, 60 per cent. showed injection fever, and when over this period, ' a good' 20 per cent. With intravenous injection, the pyrexia occurred in about 10 per cent. of cases.

The degree of pyrexia was not found to be related to the therapeutic result by Nicol, and Caldwell was unable to come to definite conclusions with regard to the duration of the fever. These results are not unexpected, as many patients show very slight clinical improvements during the incubation period and some patients undergo remissions without developing pyrexia or show a rise of temperature of a slight degree only. Bahr records a case in which parasites were found after inoculation but no fever occurred. Within three years the Wassermann reactions in the blood and cerebrospinal fluid had become negative, the globulin negative, the cells reduced and the Lange, from a paretic curve, had become 0012110000.

Clinical Condition.-Pires and Póvoa believe that the action of malaria is sometimes irritative and is thus the explanation of the secondary cutaneous manifestations sometimes found during malaria therapy.

The Blood.-In the earlier febrile paroxysms plasma-cells have been found in the blood of paralytics undergoing malarial therapy (Hattori). Saunders states that the 'shift to the left' in untreated general paralysis is corrected in 6 to 12 months by therapeutic malaria. Alberto found that the myelocytes may increase up to $\mathbf{1 5}$ per cent. in the early febrile attacks, but that they disappear completely by about the fifth paroxysm.

The Parasite.-Plasmodium ovale has been used by Nicol. This species and also $P$. malariæ (quartan malaria) are suitable for the treatment of debilitated cases, as both are milder than fever produced by $P$. vivax (benign tertian malaria) or P. falciparum (malignant tertian malaria). The marked prostration at the cessation of a course of benign tertian malaria is rare at the end of a course of quartan fever.

With P. ovale, Nicol reports that the parasites are few and that both the pyrexia and the parasites may spontaneously die out before the patient has undergone an adequate course. 
Kirschbaum treated with quartan malaria 16 cases during the year of onset of the paralysis and obtained 68.7 per cent. good remissions.

Termination of Fever.-Cases have been recorded in which improvement has occurred after inoculation with malaria although little or no pyrexia has developed. Bahr reports one case, inoculated in July, 1926, in which parasites were found but which showed no pyrexia on a four-hourly chart. No mental improvement was observed, but a definite physical improvement took place. By March, 1929, the Wassermann reactions in the blood and fluid had become negative as had also the globulin. The cells in the fluid had improved from 13 to 1.5 per c.mm. and the colloidal gold curve from 5431100000 to 0012110000 . In the second case reported by the same worker, the inoculation was performed intravenously in December, 1925. During an observation period of five weeks with a four-hourly temperature record no pyrexia occurred. The patient was reinoculated on January 11, 1926. On January 12 and 13 rises of temperature to $101 \cdot 5^{\circ} \mathrm{F}$. and $103^{\circ} \mathrm{F}$. occurred. Inoculations were again carried out on March 4, 19 and 27, but no rise of temperature developed. The malaria was checked by quinine from April 16, 1926. The patient improved mentally in a striking manner and was able to leave the hospital. For several years he has now carried out his duties satisfactorily at his former employment as a porter.

Another case has been reported by F. H. Stewart. This patient was inoculated in December, 1924, five years after the onset of slightly grandiose ideas. For about three weeks parasites were present, but no fever developed. By November an apparent complete remission had set in and the patient was discharged. Two years later, the patient was still in regular employment (potter's artizan) in which he had been since his discharge.

F. H. Stewart advises treatment by a so-called ' apyrexial' method. Although Grant and Silverston believe that from five to 10 febrile paroxysms are sufficient in place of the usual eight to 12, F. H. Stewart has used less. The malaria is terminated after the first, second or third rigor. One to three months later, the patient is reinoculated and the same procedure followed. If the improvement is insufficient for discharge further courses, up to four, have been given. Two series of unselected cases, except those moribund, were treated with the following results.

Table V

Short (Apyrexial) and Usual Methods (F. H. Stewart)

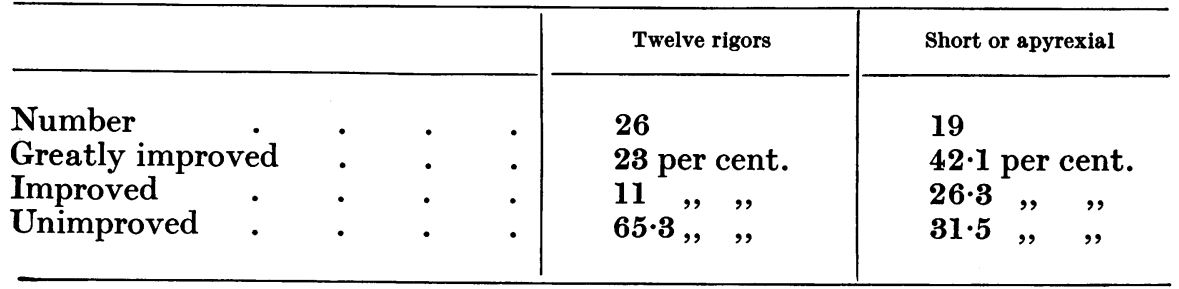


F. H. Stewart draws attention to the slight improvements of the paralytic that may occur during the incubation period of the malaria as recorded elsewhere (Therapeutic Malaria, 1927). He believes that the short or apyrexial method of treatment is more advantageous as there is a reduction of mortality and suffering and as there is no prostration after drawn-out fever. He believes that malaria should be used in the same way as a vaccine by repeated well-spaced doses adjusted to produce a gradual progressive cure.

Of cases inoculated with benign tertian malaria by means of mosquitoes, Nicol reports that about 50 per cent. relapse on one or two occasions. These relapses of malaria have been divided by James into :-

(a) Recrudescence : a return of parasites and fever up to eight weeks after the primary attack.

(b) Relapse: as a recrudescence but occurring between eight and 24 weeks after the primary attack.

(c) Recurrence : as a relapse but occurring later than 24 weeks after recovery from the primary attack.

Nicol states that these relapses, although giving a second series of febrile paroxysms to the patient, are of no benefit, the result being no better with mosquito-inoculation than with blood-inoculation, in which relapses are rare.

Accessory Treatment.-The importance of attending to the patient's general health before inoculation is rightly stressed by Nicol. This worker advises that septic foci should be dealt with. Johnson and Jefferson consider that, if any doubt exists with regard to the patient's physical condition, tryparsamide should be given before the commencement of the malaria. The urine should be examined and constipation corrected.

After the malaria, Nicol advises that Fellows' syrup be given. Leroy, Médakovitch and Prieur administered potassium iodide, mercuric biniodide, cyanide of mercury and sulfarsenol. In addition, sodium stovarsol alternating with quinby was given thrice weekly.

During the malaria, Nicol advises that the patient be kept in a warm blanket-bed and a hot drink given as soon as shivering commences. Gentian with soda may be valuable for nausea or vomiting.

\section{DANGERS AND DEATHS}

Figures now exist with regard to the number of deaths occurring in connexion with malaria used for therapeutic purposes.

Of 165 deaths, Caldwell found that $49 \cdot 4$ per cent. occurred within two months of the commencement of treatment, and of 541 deaths studied by Meagher, 40 per cent. were found to have occurred in the same period. Caldwell, reporting on 579 cases inoculated, found that 10.8 per cent. died in the first two months after inoculation. These figures are slightly higher than those for England and Wales. Meagher found, of 1,532 cases inoculated, 135 died within the first month and 74 in the second month, making a total of $7 \cdot 3$ per cent. in the first two months. 
Nicol reports an even lower rate. Within two months, with benign tertian malaria, $5 \cdot 3$ per cent. of all cases treated died, and that with 52 cases treated with malignant tertian fever 4 per cent. died.

A list of complications to be faced is given by McIntyre and McIntyre. Of 42 patients inoculated, seven showed a tendency to pyogenic infections, two developed uræmic coma (could be forestalled by systematic estimation of urea nitrogen content of blood); three collapsed and one died from circulatory collapse, three died from acute bulbar palsy and one died in a paretic seizure.

Bahr and Bruetsch report the case of a splenic abscess which perforated into the lung. Quinine stopped the malaria, but 11 days later a malarial relapse developed and death took place. The abscess was found post mortem. Meanwhile another patient had been inoculated with blood from the first case. He died three and a half months later with mitral endocarditis, splenic hæmorrhagic infarcts, and minute areas of embolic softening of the left temporosphenoidal lobe. The authors suggest that some type of streptococcus was transferred to the second patient.

The presence of albuminuria, which should be looked for daily, necessitates the termination of the malaria, although the condition may be temporary only (Nicol).

With regard to the number of parasites, Nicol considers that the malaria should be terminated if more than one parasite is found in each field when a $\frac{1}{12}$-inch objective and no. 2 ocular are used. Twenty-five fields should be examined. According to Lépine, Bourrat, Christy and Larrive malaria is contraindicated if marked depression, wasting or nephritis be present.

None of these risks are, however, so great as are those for the untreated patient. Of 624 patients admitted to mental hospitals in England and Wales in 1923 who received no treatment, 89.8 per cent. had died by the end of 1927. Again, of 549 patients admitted during 1924, and also untreated, 83.2 per cent. had died by the end of 1927 . On the other hand, of 152 patients treated with malaria in 1923 , only 46.6 per cent. were dead at the end of 1927, and of 286 patients treated in 1924, but 42 per cent. had died by the end of 1927 (Meagher). The risks run by the untreated patient are therefore about twice those run by the patient who is treated with malaria.

\section{REFERENGES}

Alberto, Gior. di batter. e immunol., 1927, $2,295$.

Assendelft, F. v., Riv. di mal., 1934, 13, 679.

Bahr, M. A., and Bruetsch, W. L., Amer. Jour. Psychiat., 1928, '7, 715.

Bahr, M. A., Ann. Rep. Central State Hosp., Indianapolis, 1929.

Belloni, G. B., Riv. di pat. nerv. e ment., 1931, March-April.

Bruetsch, W. L., Amer. Jour. Psychiat., 1932, 12, July.

Bunker, H. A., and Kirby, G. H., Amer. Jour. Psychiat., 1926, 6.

Bunker, H. A., Arch. Neurol. and Psychiat., 1928, March.

Caldwell, W. A., Rep. on 579 Cases of General Paralysis Treated by Malaria in the London County Mental Hospitals, 1931. 
Cheney, C. O., and Warner, G. L., State Hosp. Quart., 1926, 11, 603.

Cruca, M., Trans. Roy. Soc. Trop. Med. and Hyg., 1931, 24, 529.

Claude, M., and Masquin, P., Ann. méd-psychol., 1933, 14 (2), 173.

Corta, Maura, G., and Pires, W., Rev. oto.-neur.-oftal. y de cirurg. neur., 1928, September.

Dattner, B., Psych.-Neur. Woch., 1928, Nos. 23-25, June.

EdDison, H. W., Jour. Ment. Sci., 1930, 76, 66.

Ferraro, A., and Jong, T. C. C., Jour. Nerv. Ment. Dis., 1927, 65, 225.

Geary, C., Mott Memorial Volume, 1929, 201.

Grant, A. R., and Silverston, J. D., Jour. Trop. Med. and IIyg., 1926, April 15.

Hattori, cited by $H$. W. Eddison.

Hinsie, L. E., and Blalock, J. R., Amer. Jour. Psychiat., 1931, November.

Horn, L., Psych.-Neur. Woch., 1928, No. 31, August.

JAMes, S. P., Trans. Roy. Soc. Trop. Med. and Hyg., 1931, 24, 477.

Johnson, G. S., and Jefferson, R. A., Jour. Nerv. Ment. Dis., 1931, April.

Käfer, J. P., Estud. del Liq. Cefalo.-Raquideo en les Par. Gen. Malarizados, Univ. of Buenos Aires, 1932.

KIHN, B. Psych.-Neur. Woch., 1928.

Kirschibaum, W., Münch. med. Woch., No. 11, 1928.

Lépine, J., Bourrat, L., Christy, H., and Larrive, E., Jour. méd. Lyon. 1929, June.

Leroy, Médakovitch, and Prieur, M., Ann. méd.-psychol., 1928, December.

Leroy, R., and Médakovitch, G., Paralysie Générale et Malariathérapie, 1930.

Levi-Bianchini, M., and Nardi, J., Arch. gen. di neurol., psichiat. e psicoanal., 1932,

13, 121.

McIntyre, H. D., and McIntyre, A. P., Arch. Neurol. and Psychiat., 1926, August.

Malayud, W., and Wilson, R. B., Arch. Neurol. and Psychiat., 1929, December.

Masquin, P., and Borel, J., L'Encéph., 1934, 29, 73.

Meagher, E. T., General Paralysis and its Treatment by Induced Malaria, 1929.

Neustadter, M., Jour. Nerv. and Ment. Dis., 1931, June.

Nicol, W. D., Jour. Ment. Sci., 1932, 78, 843.

Nicole, J. E., and Fitzgerald, E. J., Brit. Med. Jour., 1, 1934, March 10.

OGden, W., Jour. Ment. Sci., 1930, 76, 772.

Pilcz, cited by W. A. Caldwell.

Pires, W., and Póvoa, H., Arch. Bras. di med., 1928, No. 8.

Power, T. D., Jour. Ment. Sci., 1932, 78, 878.

RAMSay, J. C., Jour. Ment. Sci., 1929, 75, 257.

REID, B., Jour. Ment. Sci., 1932, 78, 867.

Rudolf, G. DE M., Therapeutic Malaria, 1927.

Rudolf, G. de M., Mott Memorial Volume, 1929, 355.

Saunders, Jour. Lab. and Clin. Med., 1928, 13, 415.

Steel, J. P., and Nicole, J. E., Lancet, 1927, 1, 484.

Stewart, F. H., Jour. Ment. Sci., 1928, 74, 276.

Stewart, F. H., Jour. Ment. Sci., 1929, '75, 16.

Tennent, T., Jour. Ment. Sci., 1931, 7r7, 86.

Weisfeld, M., Zeits. f. d. g. Neurol. u. Psychiat., 1933, 146, 661.

Wilson, R. B., Brain, 1928, 51, 440.

Wizel, A., and Markuszewicz, R., L'Encéph., 1927, 22, 669.

Yакubovsky, A., Rev. Neur. Psych. Reflex., 1929, 4, 161. 